\title{
ON THE CHEMICAL COMPOSITION OF WOLF-RAYET STARS
}

\author{
T. NUGIS
}

W. Struve Tartu Astrophysical Observatory, Estonian S.S.R., U.S.S.R.

\begin{abstract}
The chemical composition of 5 WR stars in Cygnus are considered by using the quasi-nebular variant of Beals' model. On the basis of the general considerations which follow from this model it was concluded that the $\mathrm{C} / \mathrm{He}$ ratio for the WC stars appears to be more than 10 times higher than for normal $\mathrm{OB}$ stars and the $\mathrm{N} / \mathrm{He}$ ratio in the case of the WN stars seems also to be somewhat higher than for normal OB stars. From the solution of the equations of statistical equilibrium for the level populations, it was found that in the case of the WC stars $\mathrm{C} / \mathrm{He} \approx 1$ and in the case of the WN stars $\mathrm{N} / \mathrm{He} \approx 0.05-0.1$. For the star HD 192163 (WN6) it was found that $\mathrm{He} / \mathrm{H} \approx 4.2-7.3$ and for the other stars $\mathrm{He} / \mathrm{H} \gtrsim 10$.
\end{abstract}

\section{Introduction}

Determination of the chemical composition of WR stars is not an easy problem. The first attempts in this field have shown that it may be anomalous. Some astronomers still suppose that anomalous relative strength of the lines of certain ions in the spectra of WR stars is caused by specific excitation conditions (eg. Underhill, 1973).

Below we present a revised version of the main results presented in our recent works (Nugis, 1973a, b; Ilmas and Nugis, 1973; Nugis and Feklistova, 1973). In our study we rely on the quasi-nebular variant of Beals' model (hot core + expanding envelope). We deal with the chemical composition of 5 WR stars in Cygnus.

Some characteristics of these stars are given in Table I.

TABLE I

\begin{tabular}{llrl}
\hline Star & Sp & \multicolumn{1}{l}{$\begin{array}{l}\mathrm{T}_{*}(\mathrm{He} \mathrm{II}) \\
(\mathbf{K})\end{array}$} & $\begin{array}{l}\mathrm{T}_{\mathrm{e}}(\mathrm{He} \text { III }) \\
(\mathrm{K})\end{array}$ \\
\hline HD 192163 & WN6 & 100000 & $45000-70000$ \\
HD 191765 & WN6 & 100000 & $45000-70000$ \\
HD 193077 & WN5 & 82500 & $45000-70000$ \\
HD 192103 & WC7 & 100000 & $35000-70000$ \\
HD 192641 & WC6-7 & 85000 & $35000-70000$ \\
\hline
\end{tabular}

$T_{*}(\mathrm{He}$ II) - the core temperature found by the method of Rublev (1964) using the He II lines

$\mathrm{T}_{\mathrm{e}}(\mathrm{He}$ III) - The electron temperature in the HeIII zone found from the equation of balance for free electrons

\section{He/H Ratio}

Rublev (1972) has found that $\mathrm{He} / \mathrm{H} \approx 6-11$ for the WR stars studied here. Smith (1973) found lower limits for $\mathrm{He} / \mathrm{H}$ between 1 and 20 for other WN stars.

In our study (Ilmas and Nugis, 1973; Nugis, 1973b), we have determined the effective parameters of the zones $\mathrm{He}$ III, $\mathrm{He}$ II, $\mathrm{H}$ II and the theoretical intensities of the 
He II, He I and $\mathrm{H} \mathrm{I}$ lines by the solution of the equations of statistical equilibrium for the level populations. From the analysis of the blend $\lambda 4861$ we have found the contribution of $\mathrm{H} \mathrm{I}$. The results are given in Table II.

TABLE II

\begin{tabular}{lll}
\hline Star & Sp & He/H \\
\hline HD 192163 & WN6 & $4.2-7.3$ \\
HD 191765 & WN6 & $\gtrsim 11.7$ \\
HD 193077 & WN5 & $\gtrsim 16.7$ \\
HD 192103 & WC7 & $\gtrsim 42.5$ \\
HD 192641 & WC6-7 & $\approx 12.6$ \\
\hline
\end{tabular}

\section{3. $\mathrm{N} / \mathrm{He}$ and $\mathrm{C} / \mathrm{He}$ Ratios}

From Beals' model it follows that at predicted electron densities the number of photoionizations from the lowest levels exceeds the number of ionizations caused by electron impact and therefore normal stratification of ions must exist in the envelopes, i.e. the ions with higher ionizational potentials are located closer to the core.

We assume that

(1) the lines of different ions of a certain element are formed in different zones;

(2) at the prevailing stage of ionization the ions in the zone under consideration are situated almost fully on the ground state;

(3) in the UV region the core radiates as a black-body with the temperature $T_{*}$;

(4) the electron temperature $T_{\mathrm{e}}$ remains the same in the whole envelope;

(5) the number of photoionizations from the ground level considerably exceeds the number of photoionizations from the excited states;

(6) the volume of the transitional region between the zones is negligibly small compared to the volumes of the zones.

On the basis of these assumptions and providing that at the principal series continuum frequencies the optical depth of the zone studied is considerably greater than one, but at lower frequencies it is much smaller than one, we may conclude that for any ion $\left(A^{i+}\right)$ the following formula holds:

$$
\left\{A^{i+}\right\} \equiv\left(q \int_{x_{1}}^{\infty} \frac{x^{2}}{e^{x}-1} \mathrm{~d} x\right) / \sum_{k=2}^{\infty} C_{k} \approx \frac{A}{\mathrm{He}} \int_{V\left(A^{(i+1)+}\right)} n_{\mathrm{e}} n(\mathrm{He}) \mathrm{d} V,
$$

where $V\left(A^{(i+1)+}\right)$ is the volume of the zone $A^{(i+1)+} ; q$ is the factor which shows how many UV quanta emitted by the core at the corresponding frequencies are absorbed by the ions $A^{i+} ; C_{k}$ is the radiative-recombination coefficient; $x_{1}=h v_{1} / k T_{*} ;$ and $v_{1}$ is the threshold frequency of ionization from the ground level.

Provided the optical depth at the principal series continuum frequencies is considerably smaller than one, we ought to take into account also the recombinations to the ground level. 
By setting limits on the possible values of $q$, we can find the limiting values for the $\mathrm{N} / \mathrm{He}$ and $\mathrm{C} / \mathrm{He}$ ratios for the supposed cases of stratification for the stars under consideration.

In the case of the WN stars the N VI and N v zones are situated in the He III zone, but the N IV zone may be located either fully in the He II zone or partially also in the He III zone. In the case of the WC stars the C v zone is located in the He III zone and the $\mathrm{C}$ IV zone may be located either fully or partially in the He III zone or fully in the He II zone.

In the case of the WN stars $q \approx 1$ for $\mathrm{N} v$. Therefore we get

$$
\mathrm{N} / \mathrm{He}>\{N \mathrm{v}\}_{q=1} /\{\mathrm{He} \mathrm{III}\}_{q=1}
$$

Approximate estimations show that according to the assumption that the $\mathrm{N}$ IV zone is fully located in the He II zone $\tau_{v_{1}}^{\mathrm{N} \mathrm{mI}} \gtrsim \tau_{v_{1}}^{\mathrm{He} I} \ll 1$. Therefore we have

$$
q(\mathrm{~N} \mathrm{III}) / q(\mathrm{HeI}) \gtrsim q^{0}(\mathrm{~N} \mathrm{III}) / q^{0}(\mathrm{He} \mathrm{I})=\int_{x_{1}(\mathrm{~N} \mathrm{III)})}^{x_{1}(\mathrm{He} \mathrm{II)}} \frac{x^{2}}{e^{x}-1} \mathrm{~d} x / \int_{x_{1}(\mathrm{~N} \mathrm{III})}^{\infty} \frac{x^{2}}{e^{x}-1} \mathrm{~d} x
$$

and

$$
\mathrm{N} / \mathrm{He}>\{\mathrm{N} \mathrm{III}\}_{q=q^{\circ}(\mathrm{N} \mathrm{III})} /\{\mathrm{He} \mathrm{I}\}_{q=q^{\circ}(\mathrm{He} \mathrm{I})}
$$

Assuming that the $\mathrm{N}$ IV zone is partially located in the He III zone, we obtain that

$$
\mathrm{N} / \mathrm{He}>\left(\{\mathrm{N} \mathrm{V}\}_{q=1}+\{\mathrm{N} \text { IV }\}_{q=1}\right) /\{\mathrm{He} \mathrm{II}\}_{q=1}
$$

In the case of the WN stars studied the $\mathrm{N}$ IV zone cannot be fully located in the $\mathrm{He}$ III zone (consider that $\mathrm{N}$ II lines are very weak or absent altogether in their spectra). It follows that

$$
\mathrm{N} / \mathrm{He}<\left(\{\mathrm{N} \mathrm{v}\}_{q=1}+\{\mathrm{N} \mathrm{IV}\}_{q=1}+\{\mathrm{N} \text { III }\}_{q=1}\right) /\{\mathrm{He} \mathrm{II}\}_{q=1}
$$

\begin{tabular}{|c|c|c|c|c|}
\hline$T_{*}(\mathrm{~K})$ & $\frac{\{\mathrm{N} \mathrm{v}\}_{q=1}}{\{\mathrm{He} \text { II }\}_{q=1}}$ & $\frac{\left\{\mathrm{N} \mathrm{IIII}_{q}\right\}_{q q^{\circ}\left(\mathrm{N}_{\text {III }}\right)}}{\left\{\mathrm{He} \mathrm{I}_{q}\right\}_{q=q^{\circ}\left(\mathrm{He}_{\mathrm{I}}\right)}}$ & $\frac{\{\mathrm{N} v\}_{q=1}+\{\mathrm{N} \mathrm{IV}\}_{q=1}}{\{\mathrm{He} \mathrm{II}\}_{q=1}}$ & $\frac{\{\mathrm{N} \mathrm{v}\}_{q=1}+\{\mathrm{N} \mathrm{IV}\}_{q=1}+\{\mathrm{N} \text { III }\}_{q=1}}{\{\mathrm{He} \mathrm{II}\}_{q=1}}$ \\
\hline 70000 & 0.00020 & 0.0034 & 0.039 & 1.20 \\
\hline 82500 & 0.00059 & 0.0050 & 0.056 & 1.05 \\
\hline 100000 & 0.0017 & 0.0070 & 0.081 & 0.92 \\
\hline 120000 & 0.0038 & 0.0084 & 0.11 & 0.85 \\
\hline
\end{tabular}

The results of calculations of these limiting values for $\mathrm{N} / \mathrm{He}$ are given in Table III; for the ions, $\mathrm{N}$ IV and $\mathrm{N}$ III, the triplets' and doublets have been considered respectively.

\section{TABLE III}

$$
T_{\mathrm{e}}=60000^{\circ}
$$


Finally we obtain that the following inequality holds for the WN stars:

$$
\begin{aligned}
\min \left(\frac{\{\mathrm{N} \mathrm{III}\}_{q=q^{\circ}(\mathrm{N} \mathrm{III})}}{\{\mathrm{He} \mathrm{I}\}_{q=q^{\circ}(\mathrm{He} \mathrm{I})}}, \frac{\{\mathrm{N} \mathrm{v}\}_{q=1}+\{\mathrm{N} \mathrm{IV}\}_{q=1}}{\{\mathrm{He} \mathrm{II}\}_{q=1}}\right)<\mathrm{N} / \mathrm{He}< \\
<\frac{\{\mathrm{N} \mathrm{V}\}_{q=1}+\{\mathrm{N} \mathrm{IV}\}_{q=1}+\{\mathrm{N} \mathrm{III}\}_{q=1}}{\{\mathrm{He} \mathrm{II}\}_{q=1}} .
\end{aligned}
$$

It follows that $0.007<\mathrm{N} / \mathrm{He}<0.92$ in the case of the WN6 stars and $0.005<\mathrm{N} / \mathrm{He}<$ $<1.05$ in the case of the WN5 star.

. In the case of the WC stars there exists the $\mathrm{C}$ IV zone and $\tau_{v_{1}}^{\mathrm{C} \text { III }} \gg 1$ whereas $\tau_{v_{1}}^{\mathrm{He} \mathrm{I}} \ll 1$. Relying on the assumption that the CIV zone is fully located in the He II zone, we obtain

$$
\begin{aligned}
& \mathrm{C} / \mathrm{He}>\frac{\{\mathrm{C} \mathrm{III}\}_{q=q(\mathrm{C} \mathrm{III})}}{\{\mathrm{He} \mathrm{I}\}_{q=1}}, \\
& \left(q(\mathrm{C} \mathrm{III})=\int_{x_{1}(\mathrm{C} \mathrm{III})}^{x_{1}(\mathrm{He} \mathrm{II)}} \frac{x^{2}}{e^{x}-1} \mathrm{~d} x / \int_{x_{1}(\mathrm{C} \text { III })}^{\infty} \frac{x^{2}}{e^{x}-1} \mathrm{~d} x ; \frac{\int_{V\left(\mathrm{C}^{3+}\right)} n_{\mathrm{e}} n(\mathrm{He}) \mathrm{d} V}{\int_{V\left(\mathrm{He}^{+}\right)} n_{\mathrm{e}} n(\mathrm{He}) \mathrm{d} V} \approx 1\right)
\end{aligned}
$$

(actually $q(\mathrm{He} \mathrm{I})<1)$.

Assuming that the C IV zone is partially located in the He III zone we get

and

$$
\mathrm{C} / \mathrm{He}>\{\mathrm{C} \mathrm{IV}\}_{q=1} /\{\mathrm{He} \mathrm{II}\}_{q=1}
$$

$$
\mathrm{C} / \mathrm{He}<\left(\{\mathrm{C} \text { IV }\}_{q=1}+\{\mathrm{C} \text { III }\}_{q=1}\right) /\{\mathrm{He} \mathrm{II}\}_{q=1}
$$

TABLE IV

$T_{\mathrm{e}}=60000^{\circ}$

\begin{tabular}{rlll}
\hline$T_{*}(\mathrm{~K})$ & $\frac{\{\mathrm{C} \mathrm{III}\}_{q=q(\mathrm{C} \mathrm{III})}}{\{\mathrm{He} \mathrm{I}\}_{q=1}}$ & $\frac{\{\mathrm{C} \mathrm{IV}\}_{q=1}}{\{\mathrm{He} \mathrm{II}\}_{q=1}}$ & $\frac{\{\mathrm{C} \mathrm{IV}\}_{q=1}+\{\mathrm{C} \mathrm{III}\}_{q=1}}{\{\mathrm{He} \mathrm{III}\}_{q=1}}$ \\
\hline 70000 & 0.032 & 0.042 & 3.4 \\
85000 & 0.050 & 0.056 & 2.4 \\
100000 & 0.067 & 0.068 & 1.9 \\
120000 & 0.088 & 0.082 & 1.5 \\
\hline
\end{tabular}

The results of the computations are given in Table IV (in the case of $\mathrm{C}$ III the triplets have been considered). Therefore, the following inequality holds in the case of the WC stars:

$$
\min \left(\frac{\{\mathrm{C} \mathrm{III}\}_{q=q(\mathrm{C} \mathrm{III})}}{\{\mathrm{He} \mathrm{I}\}_{q=1}}, \frac{\{\mathrm{C} \mathrm{IV}\}_{q=1}}{\{\mathrm{He} \mathrm{II}\}_{q=1}}\right)<\mathrm{C} / \mathrm{He}<\frac{\{\mathrm{C} \mathrm{IV}\}_{q=1}+\{\mathrm{C} \mathrm{III}\}_{q=1}}{\{\mathrm{He} \mathrm{II}\}_{q=1}}
$$

For the WC7 star we get that $0.068<\mathrm{C} / \mathrm{He}<1.9$ and the WC6-7 star $0.056<\mathrm{C} / \mathrm{He}<$ $<2.4$. 
In these calculations we have taken $T_{\mathrm{e}}=60000^{\circ}$ for all the stars studied. Changing $T_{\mathrm{e}}$ by $50 \%$, we obtain values for the $\mathrm{C} / \mathrm{He}$ and $\mathrm{N} / \mathrm{He}$ ratios that differ less than $10 \%$ from those obtained above. The effect on the results of possible errors in the adopted values of $T_{*}$ (Table I) may be judged from the results in Tables III and IV. Further, it should be said that the results are not sensitive to the assumption that the number of photo-ionizations from the excited states of the ground shell (state $2 p^{2} P^{0}(\mathrm{C}$ IV, $\mathrm{N} \mathrm{v})$ ) is negligible compared to the number of photo-ionizations from the ground level. Calculations that allow for these photo-ionization processes (in which the lower limit of the integral in Equation (1) is $x_{2}=h v_{2} / k T_{*}$ and the sum $\sum_{k=k_{0}}^{\infty} C_{k}$ begins from $k=3$ ) have shown that the final limits for the $\mathrm{N} / \mathrm{He}$ and $\mathrm{C} / \mathrm{He}$ ratios change very little (less than $10 \%$ ).

In calculating the sum $\sum_{k=1}^{\infty} C_{k}$ (or $\sum_{k=2}^{\infty} C_{k}$ ) we have used here the photoionization cross-section for the ground level according to Flower (1968) and Henry (1970) and for the excited ground shell states according to Hidalgo (1968). When calculating the radiative-recombination coefficient for the upper levels we have assumed the hydrogenic approximation to be valid. When calculating the sum $\sum_{k=1}^{\infty} C_{k}$ for $\mathrm{He}$ I we have used the data from the paper by Aldrovandi and Péquignot (1973). Therefore according to the general considerations which follow from the adopted model for WR stars, it can be concluded that in the case of the WC stars the $\mathrm{C} / \mathrm{He}$ ratio appears to be more than 10 times higher than for normal OB stars and in the case of the WN stars the $\mathrm{N} / \mathrm{He}$ ratio seems also to be somewhat higher than for the normal OB stars.

To obtain exact values, it is necessary to solve the equations of statistical equilibrium for the level populations of some $\mathrm{N}$ and $\mathrm{C}$ ions. Nugis (1973a) calculates theoretical intensities for lines of $\mathrm{N} v$, triplets of $\mathrm{N}_{\text {IV }}$ and doublets of $\mathrm{N}_{\text {III }}$ and $\mathrm{C}$ IV, and deduces effective parameters for various zones. For the $C$ III lines the values of $\overline{b_{k} \beta_{i k}}\left(b_{k}=\right.$ the Menzel departure coefficient, $\beta_{i k}=$ escape probability for the quanta with $v=v_{i k}$ ) have been determined by Nugis and Feklistova (1973). It was found that, in the case of the WN6 stars, the $\mathrm{N}$ VI and $\mathrm{N} v$ zones are located in the He III zone and the $\mathrm{N}$ IV zone also overlaps this zone, and $\mathrm{N} / \mathrm{He} \approx 0.05-0.1$. In the case of the WN5 star HD 193077, the $\mathrm{N}$ IV zone is fully located in the $\mathrm{He}$ Il zone and $\mathrm{N} / \mathrm{He} \approx 0.1$. In the case of the WC stars, the $\mathrm{C} \mathrm{v}$ zone is situated in the $\mathrm{He}$ III zone and the $\mathrm{C}$ IV zone also overlaps it, and $\mathrm{C} / \mathrm{He} \approx 0.7-0.9$. The results of the determination of the $\mathrm{N} / \mathrm{He}$ and $\mathrm{C} / \mathrm{He}$ ratios are given in Table V. The factor of uncertainty in the case of these results can be approximately 3 .

The $\mathrm{N} / \mathrm{He}$ and $\mathrm{C} / \mathrm{He}$ ratios found are more dependent on the model assumptions than the $\mathrm{He} / \mathrm{H}$ ratio.

TABLE V

\begin{tabular}{|c|c|c|c|c|c|c|}
\hline Star & $\begin{array}{l}\text { HD } 192163 \\
\text { WN6 }\end{array}$ & $\begin{array}{l}\text { HD } 191765 \\
\text { WN6 }\end{array}$ & $\begin{array}{l}\text { HD } 193077 \\
\text { WN5 }\end{array}$ & $\begin{array}{l}\text { HD } 192103 \\
\text { WC7 }\end{array}$ & $\begin{array}{l}\text { HD } 192641 \\
\text { WC6-7 }\end{array}$ & $\begin{array}{l}\text { OB } \\
\text { stars }\end{array}$ \\
\hline $\mathrm{J} / \mathrm{He}$ & 0.076 & 0.046 & 0.1 & - & - & 0.0011 \\
\hline$/ \mathrm{He}$ & 0.0019 & 0.0030 & 0.0083 & 0.75 & 0.84 & 0.0015 \\
\hline
\end{tabular}


A preliminary study has shown that when using Beals' model even possible jumps in the core radiation at the principal series continuum frequencies of the $\mathrm{C}$ and $\mathrm{N}$ ions do not considerably influence the theoretical values of the $\mathrm{N} / \mathrm{He}$ and $\mathrm{C} / \mathrm{He}$ ratios. For instance, the $\mathrm{N} / \mathrm{He}$ ratio for the $\mathrm{WN}$ stars and the $\mathrm{C} / \mathrm{He}$ ratio for the WC stars turn out to be at least 10 times higher as compared with normal $O B$ stars.

\section{References}

Aldrovandi, S. M. and Péquignot, D. A.: 1973, Astron. Astrophys. $25,137$.

Flower, D. F.: 1968, in D. E. Osterbrock and R. C. O'Dell (eds.), 'Planetary Nebulae', IAU Symp. 34, 205.

Henry, R. J.: 1970, Astrophys. J. 161, 1153.

Hidalgo, M. B.: 1968, Astrophys. J. 153, 891.

Ilmas, M. and Nugis, T.: 1973, Tartu Teated 44, 19.

Nugis, T.: 1973a, Tartu Teated 44, 83.

Nugis, T.: 1973b, Tartu Teated 44, 53.

Nugis, T. and Feklistova, T.: 1973, Tartu Teated 44, 145.

Rublev, S. V.: 1972, Izv. Spets. Astrofiz. Obs. 4, 3.

Rublev, S. V.: 1964, Astron. Zh. 40, 223.

Smith, L. F.: 1973, in M. Bappu and J. Sahade (eds.), 'Wolf-Rayet and High-Temperature Stars', IAU Symp. 49, 15.

Underhill, A. B.: 1973, in M. Bappu and J. Sahade (eds.), 'Wolf-Rayet and High-Temperature Stars', IAU Symp. 49, 237. 